\title{
Association of radiographic changes of osteoarthritis, symptoms, and synovial fluid particles in 300 knees
}

\author{
Martin Pattrick, Edith Hamilton, Rob Wilson, Steve Austin, Michael Doherty
}

\begin{abstract}
Associations between compartmental distribution of radiographic changes of osteoarthritis (OA), individual features of OA (joint space loss, sclerosis, cyst, osteophyte; each scored $0-3$, and presence of synovial fluid calcium particles (calcium pyrophosphate dihydrate (CPPD) crystals identified by polarised light microscopy and other calcium particles by alizarin red positivity (ARP)) were sought in 300 osteoarthritic knees (178 patients; mean age 72, range 33-96 years). Patients whose knees were symptom free as well as those with symptoms were included. Osteoarthritis of two or three compartments but not unicompartmental OA was associated with the presence of CPPD or ARP. Involvement of any compartment (not just patellofemoral), and higher mean scores for both total and individual osteoarthritis changes (except cysts) was associated with CPPD and ARP; CPPD, but not ARP, was associated with symptoms: knees reported as having symptoms had higher mean total OA scores. Femoral cortical erosion, found more often in women, was associated with higher mean total OA score at the patellofemoral compartment but not with the presence of particles. Attrition, remodelling, and chondrocalcinosis (each scored as present or absent) occurred more often in knees with CPPD. Age did not correlate with any aspect of the $O A$ score. This study confirms the association of calcium particles with the process of OA. Unlike previous studies confined to symptomatic knees, a radiographic pattern specific to CPPD ('pyrophosphate arthropathy') did not emerge.
\end{abstract}

(Ann Rheum Dis 1993; 52: 97-103)

Osteoarthritis (OA) is often associated with deposition of crystalline material within cartilage and periarticular structures. Particles most commonly identified in synovial fluid are basic calcium phosphates (mainly hydroxyapatite ${ }^{12}$ and calcium pyrophosphate dihydrate (CPPD). ${ }^{3}$ The reasons for these associations are unknown, although it has been postulated that particles may result from shared predisposing factors that reflect underlying processes of damage or repair, and be either 'innocent bystanders' or direct pathogenic agents. ${ }^{4} 5$ Certain patterns of radiographic change within osteoarthritic knees have been associated with deposition of particular species of crystal. In the knee, for example, CPPD is reported to be associated with isolated or predominant involvement of the patellofemoral compartment, bicompartmental or tricompartmental $\mathrm{OA}$, and exuberant osteophyte and cyst formation (pyrophosphate arthropathy), ${ }^{6}$ whereas basic calcium phosphates (predominantly hydroxyapatite) have been linked to substantial attrition, paucity of osteophytes, ${ }^{5}$ and a tendency for involvement of the lateral compartment. ${ }^{7}$ For these reasons presence of calcium crystals has been used as one means of characterising 'subsets' of OA. ${ }^{8}$

Previous studies relating radiographic patterns of OA to synovial fluid particles in the $\mathrm{knee}^{2}$ have included only patients with symptoms. This is a potentially important omission because many subjects with OA have episodic symptoms or none at all. We therefore undertook the large study described. This included patients whose knees were symptom free, to broaden the range of OA examined.

\section{Patients and methods}

PATIENTS

Our study was approved by the local ethics committee. Patients were recruited from three sources: a knee OA clinic at the City Hospital, Nottingham; a hip OA clinic at the General Hospital, Nottingham; and health care of the elderly wards at the General Hospital, Nottingham. All patients had knee radiographs (anteroposterior standing and lateral 20 degrees flexion views) as part of a separate OA study. For inclusion in the present study all subjects had to have both radiographic changes of OA (joint space loss with accompanying bone response) in at least one compartment of the knee, and synovial fluid aspirated from the same knee (even in the absence of symptoms or apparent effusion/synovitis), usually on the day of the $x$ ray examination (always within six months).

\section{RADIOGRAPHIC SCORING}

Films were examined simultaneously by two observers and for each compartment a score (0-3) was given for each of joint space loss, osteophyte, subchondral sclerosis, and cysts, by the method of Thomas et al. ${ }^{9}$ Also, attrition, remodelling, chondrocalcinosis, and presence of femoral cortical erosion were recorded as present or absent.

SYNOVIAL FLUID ANALYSIS

Fresh unspun synovial fluid was examined by polarised light microscopy $(\times 400)$ for CPPD crystals (identified on the basis of characteristic morphology, signs of birefringence and extinc- 
tion angle. ${ }^{10}$ Each sample was also stained with alizarin red $S$ at $\mathrm{pH} 4 \cdot 2^{11}$ and examined under plain light $(\times 100)$ for presence of other aggregates containing calcium.

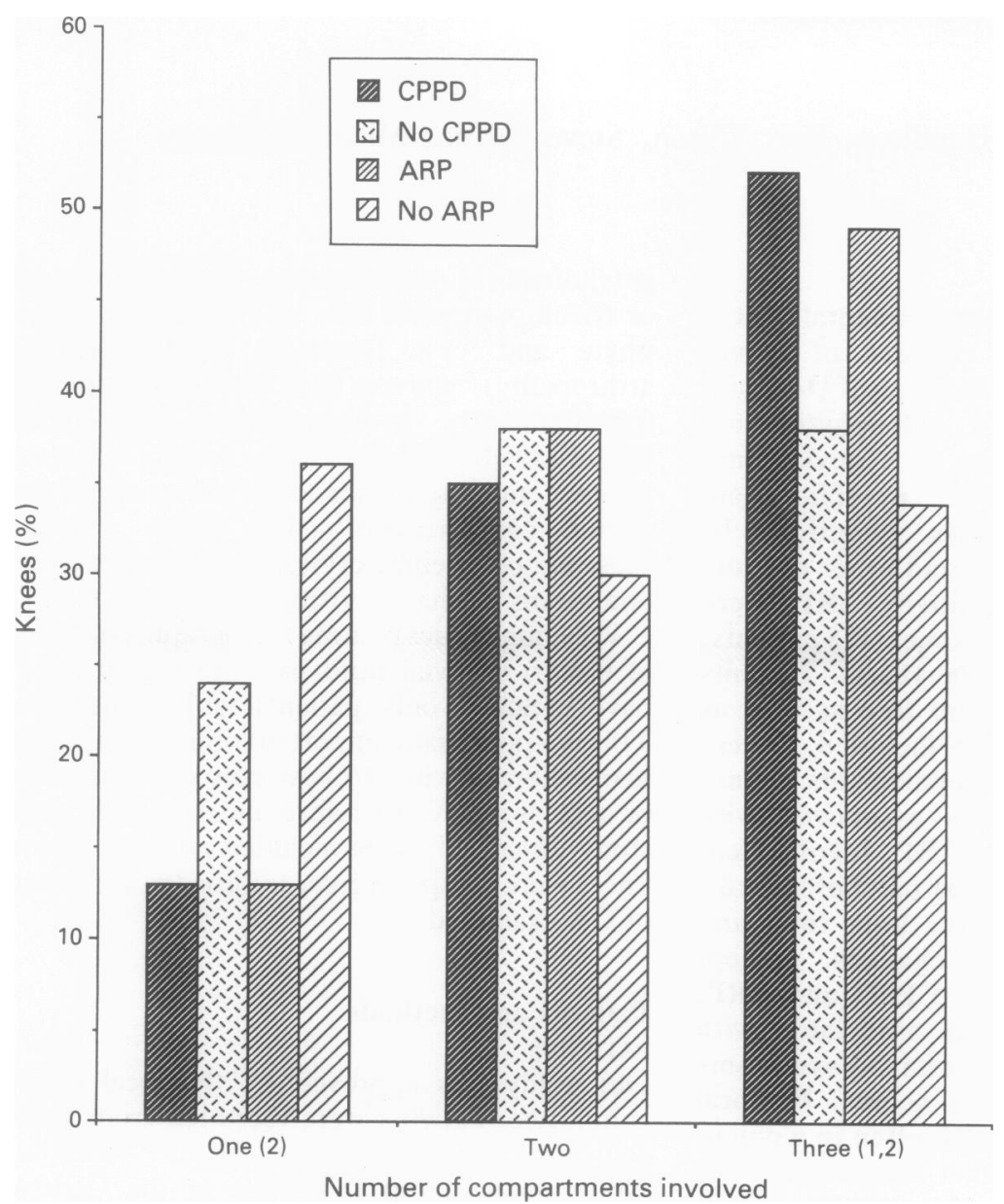

Figure 1 Compartmental involvement and presence of crystals. The number of compartments involved did not seem to reflect the presence of crystals except in tricompartmental disease where calcium pyrophosphate dihydrate (CPPD) or alizarin red positivity $(A R P)$ were more likely to occur. Significant differences: $(1)=C P P D /$ no $C P P D(p<0 \cdot 05) ;(2)=A R P /$ no $A R P(p<0 \cdot 02)$.

\section{STATISTICAL ANALYSIS}

Continuous variables were compared by MannWhitney U test and categorical data by Fisher's exact test. Correlation was by Spearman's rank correlation test. A value of $p<0.05$ was considered significant; all tests were two tailed.

\section{Results}

DEMOGRAPHIC DATA

A total of 178 patients (mean age 72 , range 33-96 years) was studied, providing 300 knees (both knees 122 patients, one knee 56 patients); $191(64 \%)$ knees were from female patients, 150 $(50 \%)$ were right knees, and 244 knees $(81 \%)$ were from patients with knee symptoms. Synovial fluid CPPD was identified in 97 (32\%) knees and alizarin red positivity (ARP) in 170 $(57 \%)$; both were identified together in 74 (25\%), and no particles were found in 107 (36\%) knees. Table 1 shows further details of groups.

\section{Number of compartments affected}

Figure 1 shows the comparison of compartmental involvement between knees with or without CPPD or ARP. For unicompartmental or bicompartmental involvement there was no difference in the incidence of CPPD. Although ARP was found in more knees with unicompartmental involvement, such involvement seemed to indicate a low chance of isolating either crystal. Tricompartmental involvement was more likely to indicate presence of CPPD or ARP with equal incidence. Lateral and either medial or patellofemoral compartment involvement was more likely to indicate presence of CPPD or ARP with similar frequency for each (fig 2).

Type of compartment affected

Involvement of any particular compartment was

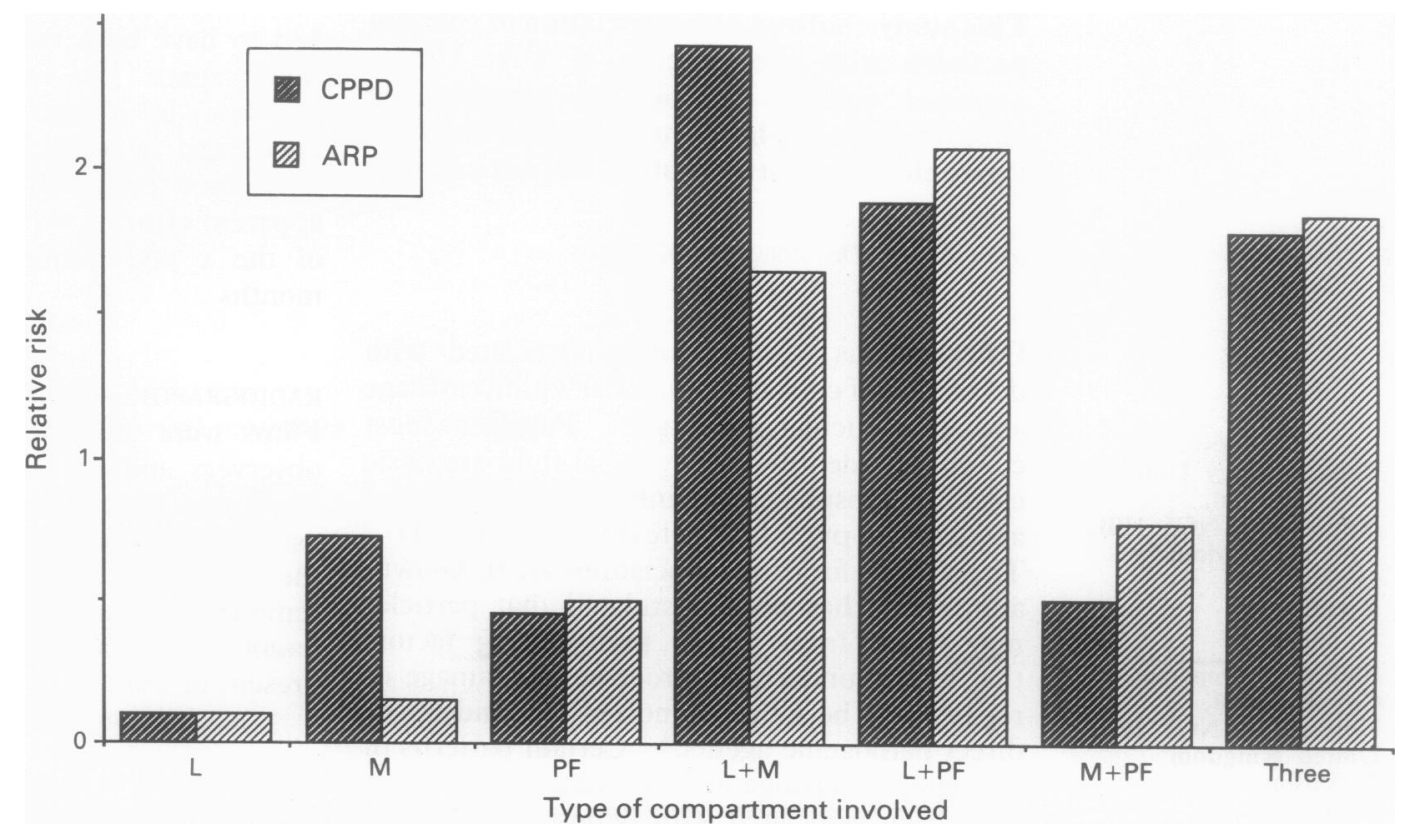

Figure 2 Relative risk of presence of crystals according to compartment involved $(L=$ lateral, $M=$ medial, $P F=$ patellofemoral $)$. Calcium pyrophosphate dihydrate $(C P P D)$ and alizarin red positivity $(A R P)$ were equally likely in tricompartmental $O A$ and in bicompartmental $O A$ affecting the lateral with either the medial or patellofemoral compartment. Unicompartmental involvement indicated a low risk of finding any crystal. 


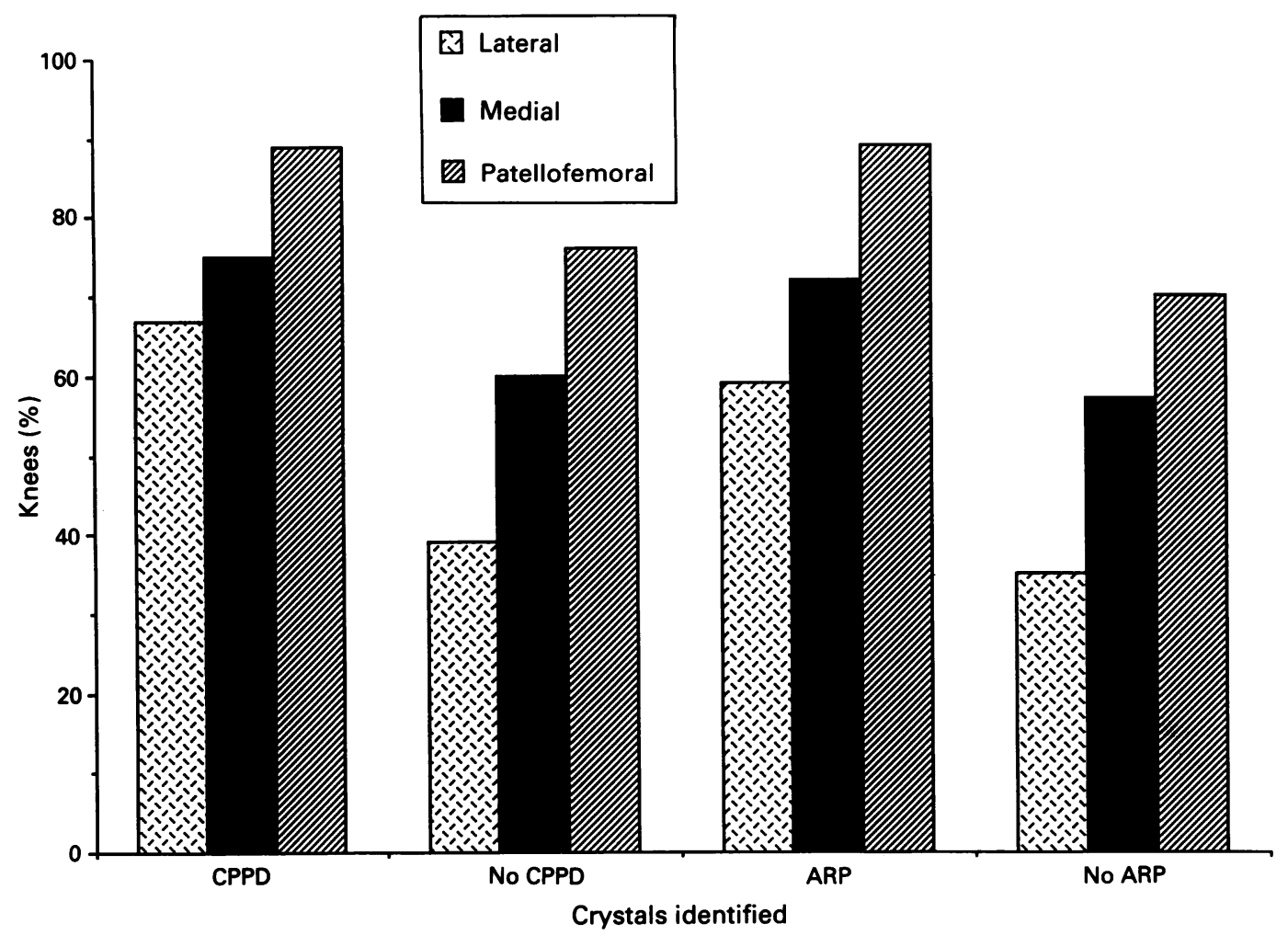

Figure 3 Type of compartment affected and crystals identified. OA of any individual compartment was more likely in knees with either calcium pyrophosphate dihydrate (CPPD) or alizarin red positivity $(A R P)$ than those without crystals; this association was not confined to the patellofemoral compartment. Comparison of those with or without CPPD or ARP showed significant differences for all compartments $(p<0 \cdot 05)$.

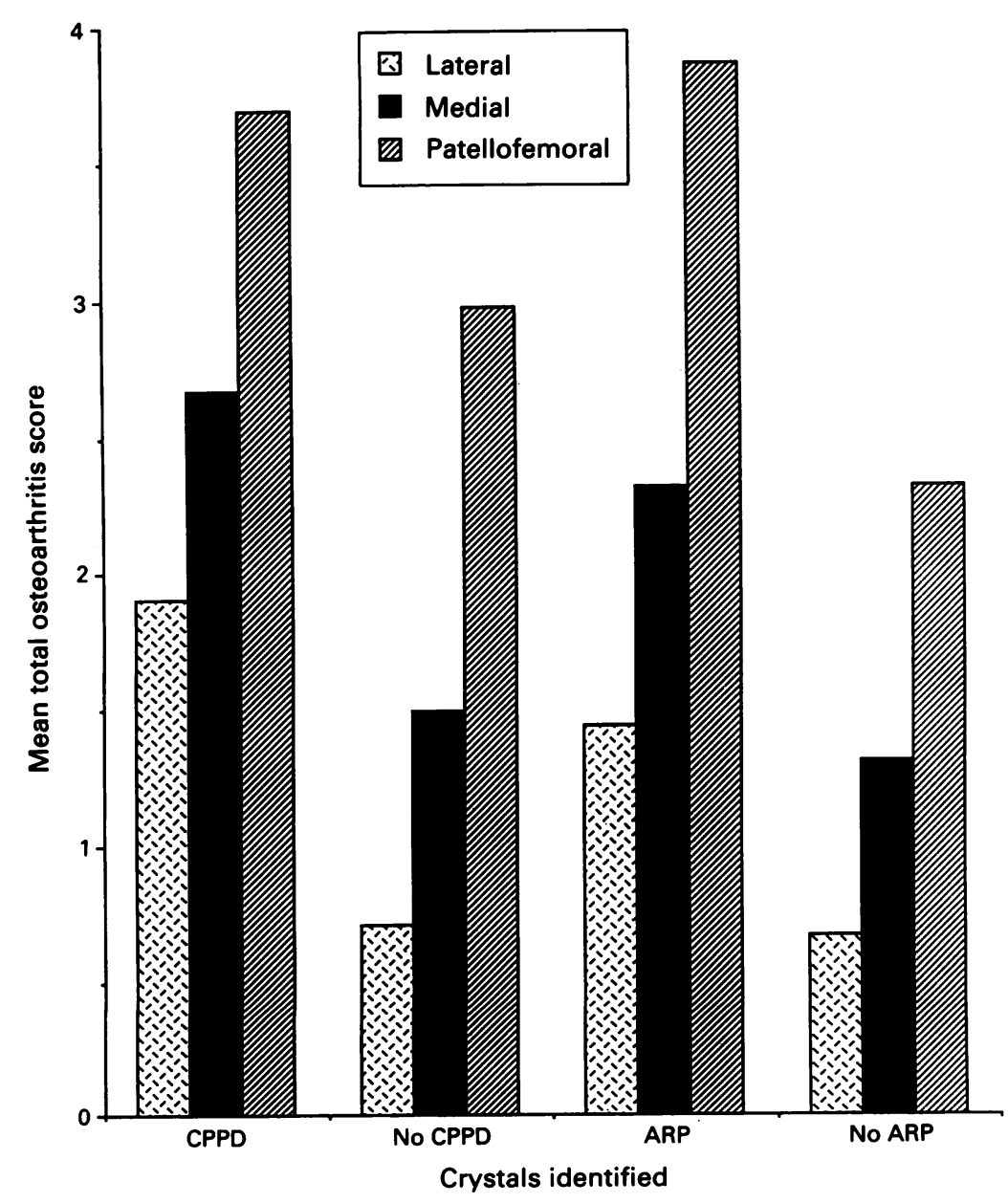

Figure 4 Mean total OA scores by compartment in knees with and without crystals. Knees with crystals had higher mean radiographic scores in all compartments. Comparison of those with or without calcium pyrophosphate dihydrate (CPPD) or alizarin red positivity $(A R P)$ showed significant differences for all compartments $(p<0.01)$. more likely in those knees with crystals (either CPPD or ARP). This association was not confined to the patellofemoral joint (fig 3).

Radiographic scores by compartment

The presence of either CPPD or ARP in a knee was associated with a considerably higher mean total OA score for all compartments (fig 4).

\section{Individual radiographic components}

The presence of either CPPD or ARP was associated with a higher mean total score for joint space loss, osteophyte and sclerosis. Cysts, however, were found equally often in knees without crystals (fig 5).

\section{Symptoms and radiographic scores}

Presence of ARP was similar in knees for which symptoms were reported and those that were symptom free (table 1). The presence of CPPD, although less frequent than ARP in knees in which symptoms were present $(36 \% v 59 \%)$, was associated with symptoms $(\mathrm{p}<0.005)$. Knees for which symptoms were reported had a higher mean total radiographic score for each compartment and higher scores for joint space loss, osteophyte, and sclerosis. The appearance of cysts was similar in both groups.

\section{Femoral cortical erosion}

Forty nine (16\%) knees had femoral cortical erosion (fig 6). These were found predominantly in women $(83 \%, p<0.001)$. The mean total 
radiographic score at the patellofemoral joint in knees with femoral cortical erosion was higher than those without $(4.0 v 3.0, \mathrm{p}=0.05)$. This difference, however, was not seen in any other compartment or in total or individual radiographic features of the OA score. Occurrence of femoral cortical erosion did not differ between knees with or without particles, or between knees with both types of particles, a single type, or neither type of particle.

Attrition, remodelling, and chondrocalcinosis Attrition was found more often in knees with CPPD crystals than those without $(14 \% v 4 \%$, $\mathrm{p}<0.01$ ), and least often in knees with femoral cortical erosion compared with those without ( $2 \%$ v 9\%, $\mathrm{p}=0.02)$. Remodelling was more frequent in knees with CPPD (16\% $v 7 \%$, $\mathrm{p}=\mathbf{0 . 0 3}$ ). Chondrocalcinosis occurred more often in knees with CPPD $(36 \% v 8 \%, \mathrm{p}<0.001)$ and in knees for which symptoms were reported $(20 \% v 4 \%, \mathrm{p}<0.02)$.

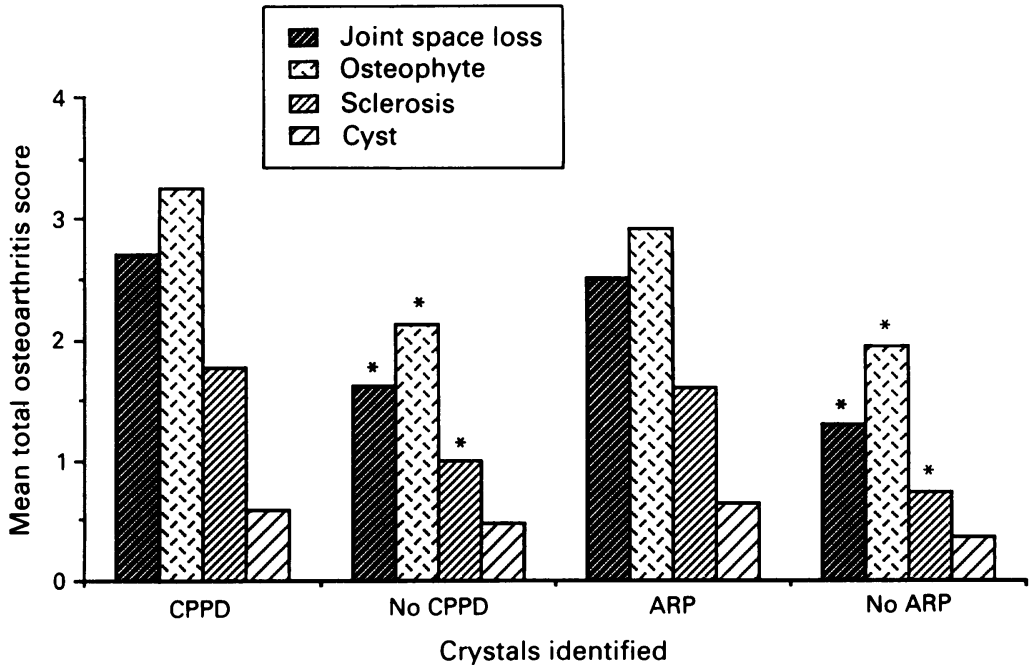

Figure 5 Mean total OA score by individual radiographic features in those with and without crystals. Foint space loss, osteophyte, and sclerosis were greater in knees with either calcium pyrophosphate dihydrate $(C P P D)$ or alizarin red positivity $(A R P)$. Cysts appeared similar in all groups. (" $p<0.01$ between those with or without $C P P D$ or $A R P$.
Comparison of knees containing either a single type, both types, or neither type of particle (table 2)

Symptoms were similar across all groups, but the presence of both types of crystals indicated a greater proportion of knees with symptoms than those with no particles $(91 \% v 74 \%, \mathrm{p}<0.01)$. Attrition showed a similar pattern (29\% v 3\%, $\mathrm{p}<0.01)$. Remodelling and femoral cortical erosion did not differ between these groups. Order of frequency of chondrocalcinosis was CPPD alone $>$ both types of particle $>$ neither type of particle $>$ ARP alone $(56 \%, 30 \%, 12 \%$, and $3 \%$ respectively).

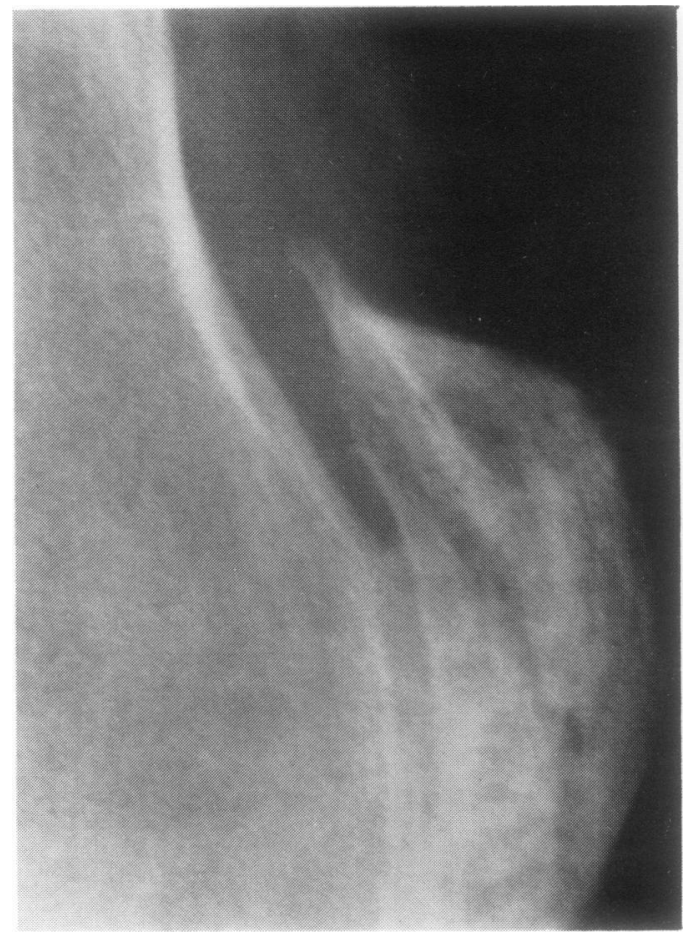

Figure 6 Lateral radiograph of knee showing femoral cortical erosion in association with patellofemoral $O A$.

Table 1 Comparison of clinical and radiographic data of knees with and without particles

\begin{tabular}{|c|c|c|c|c|c|}
\hline & $C P P D:$ no $C P P D$ & $A R P:$ : $A R P$ & S:no $S$ & $F C E:$ no $F C E$ & Total \\
\hline $\begin{array}{l}\text { No } \\
\text { Women (\%) } \\
\text { Mean age (years) }\end{array}$ & $\begin{array}{l}97: 203 \\
71: 62 \\
76: 70 \\
91: 77\end{array}$ & $\begin{array}{c}170: 130 \\
64: 63 \\
74: 69 \\
84: 77\end{array}$ & $\begin{array}{r}244: 56 \\
67: 48 \\
73: 69 \\
-\end{array}$ & $\begin{array}{l}49: 251 \\
85: 60^{*}: 1 \\
74: 72 \\
78: 82\end{array}$ & $\begin{array}{r}300 \\
63 \\
72 \\
81\end{array}$ \\
\hline $\begin{array}{l}\text { Symptomatic (\%) } \\
\text { CPPD (\%) } \\
\text { ARP (\%) } \\
\text { Chondrocalcinosis (\%) } \\
\text { Attrition (\%) } \\
\text { Remodelling (\%) } \\
\text { FCE (\%) }\end{array}$ & 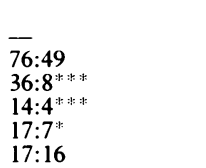 & $\begin{array}{l}43: 18^{\text {: }} \\
15: 20 \\
11: 4 \\
11: 9 \\
19: 12\end{array}$ & $\begin{array}{l}36: 17 \\
59: 46 \\
20: 4^{*} \\
9: 2 \\
12: 4 \\
16: 18\end{array}$ & $\begin{array}{r}33: 32 \\
69: 55 \\
18: 17 \\
2: 8 \\
6: 11 \\
-\end{array}$ & $\begin{array}{r}32 \\
57 \\
17 \\
8 \\
10 \\
16\end{array}$ \\
\hline $\begin{array}{l}\text { Mean OA score: } \\
\text { Lateral } \\
\text { Medial } \\
\text { Patellofemoral }\end{array}$ & 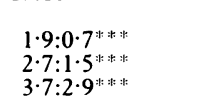 & 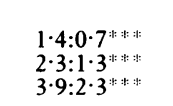 & 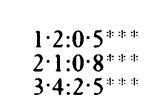 & $\begin{array}{l}0 \cdot 7: 1 \cdot 1 \\
1 \cdot 6: 1 \cdot 9 \\
4 \cdot 0: 3 \cdot 0^{*}\end{array}$ & $\begin{array}{l}1 \cdot 1 \\
1 \cdot 9 \\
3 \cdot 2\end{array}$ \\
\hline $\begin{array}{l}\text { Mean OA score: } \\
\text { Joint space loss } \\
\text { Osteophyte } \\
\text { Cyst } \\
\text { Sclerosis }\end{array}$ & $\begin{array}{l}2 \cdot 7: 1 \cdot 6^{* * *} \\
3 \cdot 3: 2 \cdot 1^{* * *} \\
0 \cdot 6: 0 \cdot 5 \\
1 \cdot 7: 0 \cdot 9\end{array}$ & $\begin{array}{l}2 \cdot 5: 1 \cdot 3^{\text {*n: }} \\
2 \cdot 9: 1 \cdot 9^{\text {*: }} \\
0 \cdot 6: 0 \cdot 4 \\
1 \cdot 6: 0 \cdot 7^{*}\end{array}$ & $\begin{array}{l}2 \cdot 2: 1 \cdot 1 \\
2 \cdot 7: 1 \cdot 5^{\text {t: }} \\
0 \cdot 6: 0 \cdot 3 \\
1 \cdot 3: 0 \\
\end{array}$ & $\begin{array}{l}2 \cdot 2: 1 \cdot 9 \\
2 \cdot 4: 2 \cdot 5 \\
0 \cdot 4: 0 \cdot 5 \\
1 \cdot 4: 1 \cdot 2\end{array}$ & $\begin{array}{l}2 \cdot 0 \\
2.5 \\
0.5 \\
1.2\end{array}$ \\
\hline Total OA score & $8 \cdot 3: 5 \cdot 2^{* * 1 *}$ & $7 \cdot 6: 4 \cdot 3^{* * *}$ & $6 \cdot 7: 3 \cdot 8$ & $6 \cdot 4: 6 \cdot 1$ & $6 \cdot 2$ \\
\hline
\end{tabular}

$\mathrm{p}<0.05 ; " \mathrm{p}<0.01 ;$ *** $\mathrm{p}<0.001$.

All categorical data are expressed as a percentage of the total group (except No). $\mathrm{S}=$ symptoms; $\mathrm{FCE}=$ femoral cortical erosion; ARP $=$ alizarin red positivity. 
Table 2 Comparison of knees with only one type, both types, or neither type of particle

\begin{tabular}{|c|c|c|c|c|c|}
\hline & $\begin{array}{l}\text { CPPD } \\
\text { only }\end{array}$ & $\begin{array}{l}\text { ARP } \\
\text { only }\end{array}$ & Both & Neither & Significant differences \\
\hline $\begin{array}{l}\text { No } \\
\text { Women (\%) } \\
\text { Mean age (years) } \\
\text { Symptomatic (\%) }\end{array}$ & $\begin{array}{l}23 \\
74 \\
75 \\
91\end{array}$ & $\begin{array}{l}95 \\
63 \\
73 \\
80\end{array}$ & $\begin{array}{l}74 \\
73 \\
76 \\
91\end{array}$ & $\begin{array}{r}107 \\
60 \\
67 \\
74\end{array}$ & $\mathbf{B N}^{* *}$ \\
\hline Chondrocalcinosis (\%) & 56 & 3 & 30 & 12 & 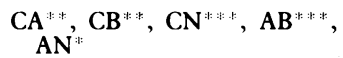 \\
\hline $\begin{array}{l}\text { Attrition (\%) } \\
\text { Remodelling (\%) } \\
\text { FCE (\%) }\end{array}$ & $\begin{array}{l}29 \\
18 \\
13\end{array}$ & $\begin{array}{r}6 \\
7 \\
20\end{array}$ & $\begin{array}{l}16 \\
16 \\
18\end{array}$ & $\begin{array}{r}3 \\
7 \\
12\end{array}$ & $\mathrm{BN}^{*}$ \\
\hline $\begin{array}{l}\text { Mean OA score } \\
\text { by compartment: } \\
\text { Lateral } \\
\text { Medial } \\
\text { Patellofemoral }\end{array}$ & $\begin{array}{l}1 \cdot 1 \\
1 \cdot 9 \\
2 \cdot 4\end{array}$ & $\begin{array}{l}0 \cdot 9 \\
1.9 \\
3 \cdot 7\end{array}$ & $\begin{array}{l}2 \cdot 1 \\
2 \cdot 9 \\
4 \cdot 1\end{array}$ & $\begin{array}{l}0 \cdot 6 \\
1 \cdot 1 \\
2 \cdot 3\end{array}$ & 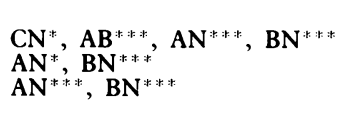 \\
\hline $\begin{array}{l}\text { Mean OA score by } \\
\text { individual OA features: } \\
\text { Joint space loss } \\
\text { Osteophyte } \\
\text { Cyst } \\
\text { Sclerosis }\end{array}$ & $\begin{array}{l}1 \cdot 5 \\
2 \cdot 6 \\
0 \cdot 3 \\
1 \cdot 1\end{array}$ & $\begin{array}{l}2 \cdot 5 \\
2 \cdot 5 \\
0 \cdot 5 \\
1 \cdot 4\end{array}$ & $\begin{array}{l}3 \cdot 1 \\
3 \cdot 5 \\
0 \cdot 7 \\
1 \cdot 9\end{array}$ & $\begin{array}{l}1 \cdot 2 \\
1 \cdot 8 \\
0 \cdot 4 \\
0 \cdot 7\end{array}$ & 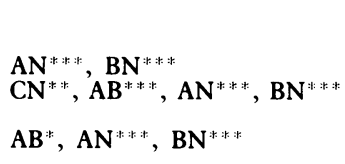 \\
\hline Total OA score & $6 \cdot 4$ & $5 \cdot 4$ & $9 \cdot 2$ & $4 \cdot 1$ & $\mathbf{B N}^{* * *}$ \\
\hline
\end{tabular}

${ }^{*} \mathrm{p}<0.05 ;{ }^{* *} \mathrm{p}<0.01 ;{ }^{* * *} \mathrm{p}<0.001$; where no significant differences were present, comparisons have been omitted for clarity. All categorical data are expressed as a percentage of the total group (except No). FCE $=$ femoral cortical erosions; $A R P=a$ alizarin red

positivity.

The order of mean total OA scores was both types of particles $>$ CPPD alone $=$ ARP alone $>$ neither type of particle $(9 \cdot 2,6 \cdot 4,5 \cdot 4$, and $4 \cdot 1$ respectively). This sequence was reflected in the individual features of the radiographic score, with the notable exception of cysts, which were similar in all groups. Differences were greatest in the lateral compartment; both types of particle $=\mathrm{CPPD}$ alone $=\mathrm{ARP}$ alone $>$ neither particle $(2 \cdot 1,1 \cdot 1,0 \cdot 9,0.6$ respectively). The patellofemoral and medial compartments were similar except for knees with neither type of particle. These had a smaller score than those with only ARP or both types of particles (lateral; $0.6 v 0.9$ and $2 \cdot 2$ : patellofemoral $2.3 v$ $3 \cdot 7$ and $4 \cdot 1$ respectively).

Correlation of aging and radiographic score either by compartment or by individual $O A$ feature No association was apparent.

\section{Discussion}

This study confirms that calcium crystals are commonly found in the osteoarthritic knee, with frequencies of crystal presence similar to those previously described. ${ }^{17}$ Unlike previous reports, however, we studied a large number of knees and included knees from patients both with and without knee symptoms. Both the number of patients and the low synovial fluid volumes often obtained in part determined the method of crystal identification that we used. Precise identification of crystals requires methods such as $x$ ray diffraction, infrared spectrophotometry, or electron microscopy. ${ }^{3} \mathrm{~A}$ specific semiquantitative method with radiolabelled diphosphonate binding to detect hydroxyapatite has also been described. ${ }^{2}$ Such methods, however, have problems in requirement of large yields of crystals, expense, and time. We therefore used polarised light microscopy to identify CPPD crystals, and alizarin red $\mathrm{S}$ at acidic $\mathrm{pH}$ to screen for other calcium phosphate particles, including apatite. ${ }^{11}$ This compromise, although reducing specificity of particle identification, permitted examination of a large number and wide range of osteoarthritic knees.

Alizarin red is a non-specific calcium stain, but at the acidic $\mathrm{pH}$ used in this study its specificity for apatite is increased. ${ }^{12}$ Although cross staining with CPPD could account for some cases where both CPPD and ARP were detected, morphological and polarised light characteristics were taken into account (apatite particles inevitably aggregate and are nonbirefringent, whereas CPPD crystals are usually separate and show weak positive birefringence. ${ }^{3}$ These factors and the lack of correlation between identification of CPPD and $A R P^{13}$ suggest that cross staining is not a frequent cause of false positives with this technique. As well as possible false positives, a negative finding in synovial fluid does not exclude the presence of calcium crystals. ${ }^{14} \mathrm{~A}$ further confounding factor is that positive identification of particles in synovial fluid can be an intermittent phenomenon when serial sampling the same joint. ${ }^{13}$ Such uncertainties are, however, an inherent feature of all studies on synovial fluid particles. Although only one aspiration of each knee was undertaken for the purposes of this survey, the large number of knees examined should reduce the bias that results from such problems.

The distribution of osteoarthritic changes within the compartments of the knee did not seem to differ according to the crystals identified. Both CPPD and ARP were found equally in knees with tricompartmental and bicompartmental involvement, and the best association seemed to be the low likelihood of finding any calcium particle in unicompartmental OA. In particular we did not find the reported association of CPPD and patellofemoral OA, ${ }^{15}$ nor a distinctive pattern for 'pyrophosphate' or 
'apatite associated' arthropathy on the basis of compartmental distribution. ${ }^{15} 16$ Higher mean scores for OA were associated with the presence of crystals, although again this was seen equally for CPPD and ARP. Alizarin red positivity was not associated with attrition, whereas CPPD was associated with remodelling but also attrition, so that a clear difference in bone response between different calcium particles was not found. ${ }^{17}$

The present data therefore suggest that increased $\mathrm{OA}$ of the knee, in terms of both distribution and severity of radiographic structural change, is associated with an increased likelihood of detection of calcium particles. This association was maintained for each individual component of the radiographic score for $\mathrm{OA}$ with the notable exception of cysts. This may indicate a particular role for cysts in OA or, more likely, the lack of sensitivity of current techniques in assessing 'cysts' on plain radiographs. Irrespective of the nature of the crystals identified, there were differences between knees having a combination of CPPD and ARP, a single crystal species, or no discernible crystal. Knees with both types of crystal rather than neither were more likely to show symptoms, to show evidence of attrition, and to have a greater radiographic score for $\mathrm{OA}$. Interestingly the differences in OA scores were largely accounted for by changes in the lateral compartment, which is least affected in sporadic OA. ${ }^{18}$ Lack of correlation between ageing and any aspect of the OA score was not unexpected as the study was confined to a narrow age range.

The apparent association of CPPD and other calcium particles with increasing distribution and severity of $\mathrm{OA}$ could be explained by progressive alteration of the physicochemical environment in cartilage attributable to the osteoarthritic process, which predisposes to nucleation and growth of calcium crystals. This change, analogous to 'field change' in the context of neoplasia, could involve a decrease in natural inhibitors (for example, proteoglycan) ${ }^{19}$ or increase in promoters (for example, lipoprotein $)^{19}$ of crystal formation and growth, or local changes in concentration or availability of relevant ions. Changes in such factors, which are little studied and poorly understood, might not be specific to single crystal species and result in an increasing chance of calcium crystal formation in association with $\mathrm{OA}$. The reported associations between CPPD (and 'mixed crystal deposition'20) with bicompartmental and tricompartmental involvement and profuse bone changes at the $\mathrm{knee}^{17}$ might, therefore, reflect a different stage of the process of $\mathrm{OA}$ (late, widespread) rather than a separate 'subset' of OA. Long term prospective studies of early knee $\mathrm{OA}$ are required to resolve these issues. Although we included knees from patients without knee symptoms all knees showed radiographic $\mathrm{OA}$ and the incidence of calcium particles in normal knees remains to be assessed although it would seem to be low. ${ }^{21}$ Furthermore, this study was confined to the knee, and whether similar associations occur with OA at other joints remains to be determined.

Although discordance between symptoms and structural change in $O A$ is often seen in individual patients, ${ }^{22}$ the increased radiographic OA score in knees showing symptoms in this study concurs with population based surveys at this site. ${ }^{23} 24$ The mechanisms of pain production in OA are ill defined but may relate to changes in bone and intracapsular and periarticular structures. ${ }^{25}{ }^{26}$ Progressive architectural change, reflected by radiographic score, might be expected to increase the opportunity of pain production by all of these mechanisms. Association of both CPPD and chondrocalcinosis with symptoms may reflect the inflammatory nature of CPPD crystals: ${ }^{27}$ detailed characterisation of symptoms and signs, however, were not undertaken for the purposes of this study.

We found a surprisingly high incidence of femoral cortical erosion (16\% of knees), which was strongly associated with female knees (all other radiographic findings showed a similar sex distribution). Cortical erosion associated with patellofemoral OA was negatively associated with attrition and showed no associations with crystals, remodelling, or OA at other sites. This apparent association with local but not generalised $\mathrm{OA}$ at the knee might support local mechanical factors in causation. ${ }^{28} 29$

In summary, we have confirmed the association of crystals with the process recognised as OA, but have been unable to identify crystal specific changes. These data are most compatible with a generalised change in the intra-articular environment that predisposes to, but is not dependent on, crystal formation.

We are grateful to the Arthritis and Rheumatism Council for financial support.

1 Gibilsco P A, Schumacher H, Hollander J L, Soper K A Synovial fluid crystals in osteoarthritis. Arthritis Rheum 1985; 28: $511-5$.

2 Halverson P B, McCarty D J. Identification of hydroxyapatite crystals in synovial fluid. Arthritis Rheum 1979; 22: 389-95.

3 McCarty D J. Synovial fluid. In: McCarthy D J, ed. Arthritis and allied conditions. 10th ed. Philadelphia: Lea and Febiger, 1985: 54-75.

4 Schumacher H R. Osteoarthritis: the role of articular crystals. Arizona Medicine 1978; 25: 22-5.

5 Dieppe P A, Crocher P R, Corhe C F, Doyle D V Huskinsson E C, Willoughby D A. Synovial fluid crystals. Qf Med 1979; 48: 533-53.

6 Doherty M, Dieppe P A. Clinical aspects of calcium pyrophosphate dihydrate crystal deposition. Rheum $D$ is Clin North Am 1988; 14: 395-414.

7 Halverson P, McCarty D J. Patterns of radiographic abnormalities associated with basic calcium phosphate and calcium pyrophosphate dihydrate deposition in the knee. calcium pyrophosphate dihydrate

8 Peyron J C. Epidemiological and aetiologic approach of osteoarthritis. Semin Arthritis Rheum 1979; 8: 288-306.

9 Thomas R A, Resnick D, Alazrai N P, et al. Compartmenta study of available diagnostic modalities. Radiology 1975 116: $585-94$

10 Chayen J. Polarised light microscopy: principles and practice for the rheumatologist. Ann Rheum Dis 1983; 42 (suppl):

11 Harnando P, Reginato A J, Schumacher H R. Alizarin red S as a screening test to detect calcium compounds in synovial fluid. Arthritis Rheum 1983; 26: 191-ziouv.

12 Puchtler $\mathrm{H}$, Meloan S N, Terry M S. On the history and mechanism of alizarin and alizarin red $\mathrm{S}$ stain for calcium. mechanism of alizarin and alizarin red $S$

13 Hamilton E, Pattrick M, Hornby J, Derrick G, Doherty M. Synovial fluid calcium pyrophosphate dihydrate crystals Synovial fluid calcium pyrophosphate dihydrate crystals
and alizarin red positivity: analysis of 3000 samples. $B r \mathcal{F}$ and alizarin red positivity: a
Rheumatol 1990; 29: 101-4.

14 Dieppe P A, Watt I. Crystal deposition in osteoarthritis: an opportunistic event? In: Sokoloff $L$, ed. Clinics in rheumatic opportunistic event? In: Sokoloff $L$, ed. Clinics in rhe
diseases II.2. Philadelphia: Saunders, 1985: 367-92.

15 McCarty D J, Kohn N N, Faires J S. The significance of calcium phosphate crystals in the synovial fluid of arthritis patients: the pseudogout syndrome. I. Clinical aspects. Ann Intern Med 1962; 56: 711-37.

16 Dieppe P A, Crocker P, Huskisson E C, Willoughby D A. Apatite deposition disease. A new arthropathy. Lancet 1976; i: $266-8$. 
17 Dieppe P A, Campion G, Doherty M. Mixed crysta deposition. Rheum Dis Clin North Am 1988; 14: 415-26.

18 Lawrence J S, Degraat R, Laine V A I. Degenerative join disease in random samples and occupational groups. In Kellgren J A, Jeffrey M R, Ball J, eds. The epidemiology of chronic rheumatism, Oxford: Blackwell, 1963: 68-119.

19 Barrett R M, Lehr J R, McCarty D J. Factors affecting the solubility of CPPD crystals. $\mathcal{f}$ Clin Invest 1975; 56: 1571-9.

20 Dieppe P A, Doyle D V, Huskisson E C, Willoughby D A Crocker F R. Mixed crystal deposition disease and osteoCrocker F R. Mixed crystal

21 Hamilton E, Pattrick $M$, Doherty $M$. Inorganic pyrophosphate, nucleoside triphosphate pyrophospatase and cartilage fragments in normal human synovial fluid. $\mathrm{Br} \mathcal{J}$ Rheumatol 1991; 30: 260-4.

22 Foreman M D, Malavret R, Kaplan D. A survey of osteoarthritis of the knee in the elderly. $\mathcal{F}$ Rheumatol 1983 10: 282

23 Lawrence J S, Bramner J M, Bier F. Osteoarthritis-prevalence in the population and relationship between symptoms and $x$-ray changes. Ann Rheum Dis 1966; 25: 1-24.

24 Wood P N. Osteoarthritis in the community. In: Wright V ed. Clinics in rheumatic disease. Vol 2. London: Saunders, 1976: 495-507.

25 Meritt J L. Soft tissue mechanisms of pain in osteoarthritis Semin Arthritis Rheum 1989; 18 (suppl): 51-6.

26 Kantor J G. Concepts in pain control. Semin Arthritis Rheum 1989; 18 (suppl): 94-9.

27 McCarty D J, Phelps P, Pyenson J. Crystal induced inflammation in canine joints. I. An experimental method with quantification of the host response. $\mathcal{F}$ Exp Med 1968; with quantification of the host response. $\mathcal{F}$ Exp Med 1968;

28 Goodfellow J W, Hungerford D S, Zindel M. Patello-femoral joint mechanics and pathology: functional anatomy of the patello-femoral joint. F Bone foint Surg 1976; 58B: 287-90.

29 Seedhom B B, Taheda T, Tsoboku M, Wright V. Mechanical factors and patello-femoral osteoarthritis. Ann Rheum Dis 1979; 38: 307-16. 